\title{
Emergency department diagnosis of supraspinatus tendon calcification and shoulder impingement syndrome using bedside ultrasonography
}

\author{
David C Riley*, Martha Kaufman, Theresa M Ward, Yesenia Acevedo, Rodney Guerra and Adenike Folorunsho
}

\begin{abstract}
A 45-year-old woman presented to the emergency department with a 2-day history of severe left shoulder pain made worse with movement. Emergency department (ED) bedside point-of-care static and dynamic ultrasound examination of the supraspinatus tendon revealed supraspinatus tendon calcification with impingement syndrome, and the patient was urgently referred to orthopedics after ED pain control was achieved. Bedside shoulder and supraspinatus tendon evaluation with static and dynamic ultrasonography can assist in the rapid diagnosis of supraspinatus tendon calcification and supraspinatus tendon impingement syndrome in the emergency department.
\end{abstract}

Keywords: Ultrasound, Emergency department, Supraspinatus tendon calcification, Impingement syndrome

\section{Background}

The prevalence of supraspinatus tendon calcification causing shoulder pain has been reported to be as high as $6.8 \%$, mainly due to the supraspinatus tendon subacromial impingement syndrome with shoulder pain causing limited motion [1]. Radiology department diagnostic ultrasound evaluation of supraspinatus tendon calcification with subacromial impingement syndrome has been reported to be more specific (95\% to 96\%) than sensitive ( $71 \%$ to $81 \%)$ in adult patients, and supraspinatus tendon calcification with subacromial impingement syndrome diagnosed through ultrasonography has been reported in young athletes who perform overhead sports such as tennis, volleyball, and swimming [2-8]. Supraspinatus tendon calcification has also been reported to cause shoulder pain in children [9]. Undiagnosed and untreated supraspinatus tendon calcification with subacromial impingement syndrome can progress to severe forms of subacromial and subdeltoid bursitis, and even more serious surgical problems such as bicipital tendonitis with rupture of the long head of the biceps tendon, adhesive capsulitis, and

\footnotetext{
* Correspondence: dr499@columbia.edu

Emergency Medicine Department, Columbia University Medical Center, New York, NY, USA
}

\section{Springer}

rotator cuff tears [5-7]. Emergency physicians using pointof-care bedside ultrasonography to rapidly diagnose supraspinatus tendon calcification with subacromial impingement syndrome can expedite rapid musculoskeletal specialist referral to potentially improve patient outcomes.

\section{Case presentation}

A 45-year-old right-handed woman with a past medical history of hypertension and stroke presented to the emergency department (ED) with a 2-day history of severe left shoulder progressively worsening pain and limited movement due to the pain. Aside from the pain on her left shoulder, the patient reported no associated trauma, weakness, numbness, left upper-extremity tingling, shortness of breath, chest pain, or fever. Her ED vital signs were as follows: temperature $36.9^{\circ} \mathrm{C}$, blood pressure 132/70 $\mathrm{mmHg}$, heart rate $73 \mathrm{bpm}$, respiratory rate $18 \mathrm{bpm}$, and oxygen saturation $98 \%$ on room air. The patient's electrocardiogram showed a normal sinus rhythm with no ST or T-wave abnormalities. Physical examination results were normal except for the left shoulder exam, where patient expressed severe pain with passive and active abduction of the humerus and some mild trapezial muscle and subacromial and subdeltoid 
area tenderness to palpation near the greater tuberosity of the humerus. The patient was able to actively abduct her left shoulder to $60^{\circ}$, but pain limited her ability to abduct further. The left arm was neurovascularly intact with normal motor and sensory functions of radial, median, ulnar, and axillary nerves. The patient had 5/5 motor strength of her shoulder upon internal and external rotation and with forearm supination; she stated no tenderness along her anterior shoulder near the long head of the biceps tendon in the bicipital groove.

On initial assessment, the triage nurse suspecting possible shoulder calcific tendonitis, considering the severe pain that the patient was experiencing, notified the ED physician assistant and the ED physician to facilitate rapid pain medication administration and a rapid bedside ED ultrasound evaluation of the patient's left shoulder. A focused bedside ED ultrasound examination of the patient's supraspinatus tendon was performed by an ultrasonographer ED attending physician, with more than 10 years of experience, after administering opiate analgesia to the patient (see Additional files 1 and 2 available as supporting information in the online version of this paper). With the patient in modified Crass position (where the patient placed her palm on her ipsilateral iliac wing and moved her elbow as posterior as possible), long-axis evaluation of the patient's supraspinatus tendon revealed calcification near the attachment to the greater tuberosity of the humerus, and a dynamic bedside ultrasound long-axis evaluation of the patient's supraspinatus tendon showed elevation of the greater tuberosity cranially to the level of the acromion and impingement of the supraspinatus tendon underneath the acromion of the scapula when the patient actively abducted her left humerus (Figures 1 and 2; Additional files 1 and 2). With a dynamic humerus abduction maneuver, we were able to directly see the calcified and thickened supraspinatus tendon causing the impinge-

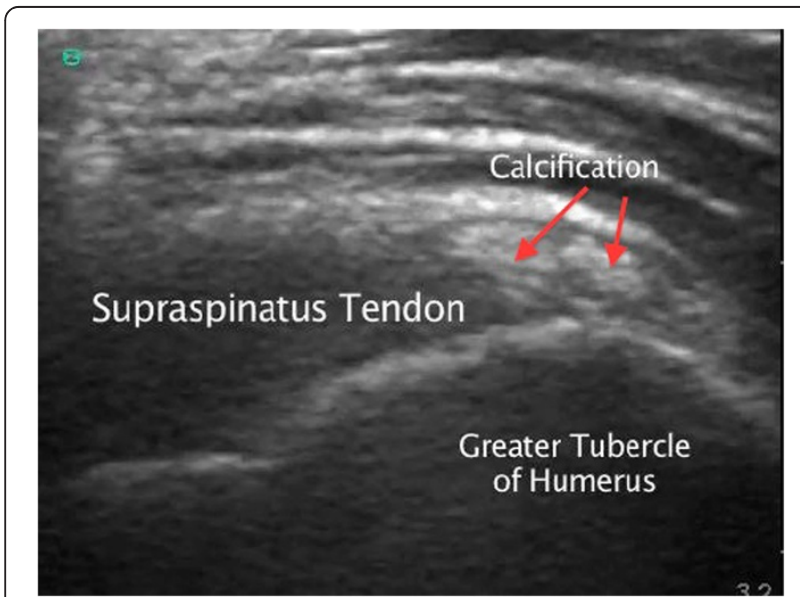

Figure 1 Supraspinatus tendon calcification.

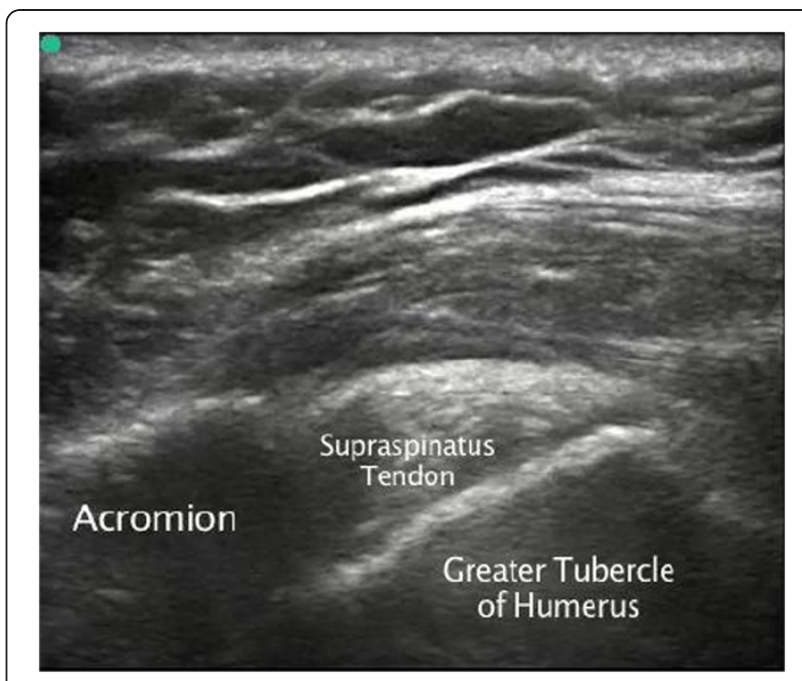

Figure 2 Supraspinatus tendon impingement under the acromion.

ment syndrome with limited abduction, and this would not be possible with X-ray calcification diagnosis alone.

In the radiology department, proximal humerus plain film radiography showed two small soft tissue calcifications in the region of the supraspinatus tendon of the left shoulder, likely thought to be calcific tendinitis (Figure 3). The patient's pain was controlled in the ED, and she was treated and released with oral pain medications, a left arm sling, and urgent orthopedic follow-up.

\section{Discussion}

Supraspinatus tendon calcification is thought to be due to the deposition of calcium hydroxyapatite crystals inside the supraspinatus tendon near the greater tuberosity

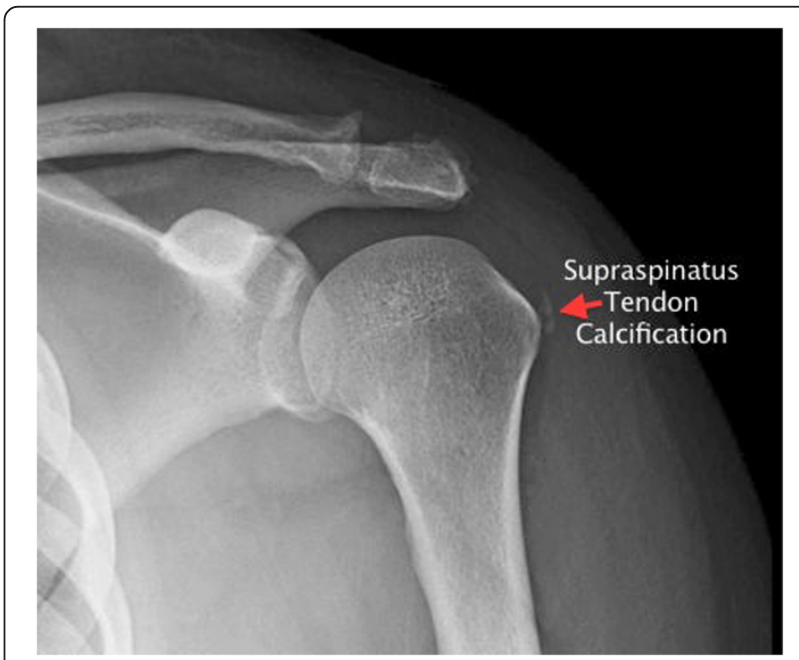

Figure 3 Plain film radiograph of the proximal humerus with supraspinatus tendon calcification. 
of the humerus insertion point, and the calcium deposits in the supraspinatus tendon may be due to fibrosis, necrosis, tendon degeneration, or systemic non-degenerative causes $[1,8]$. Supraspinatus tendon calcification may lead to tendon thickening which could lead to impingement under the acromion of the scapula, causing an impingement syndrome and severe pain upon humerus abduction [1].

Dr. Charles Neer in 1972 was the first person to describe subacromial impingement syndrome as a distinct clinical problem $[2,3,7]$. Neer described three stages of subacromial impingement: stage I impingement involves edema and hemorrhage of the subacromial-subdeltoid bursa and rotator cuff, and typically occurs in patients less than 25 years old; stage II impingement involves tendinopathy, such as fibrosis or tendinosis and calcific tendonitis, usually occurring in patients 25 to 40 years old; and stage III impingement typically involves surgical problems such as a rotator cuff tear and usually manifests in patients older than 40 years old [3,7]. Bigliani and Levine have classified the causes of subacromial impingement syndrome as either intrinsic/intratendinous or extrinsic/extratendinous, and each group can be either a primary etiology that directly causes the impingement or a secondary etiology which is the result of another process such as instability or neurologic injury [7]. Examples of intrinsic primary impingement are degenerative tendinopathy and calcification of the supraspinatus tendon that can lead to tendon thickening and impingement, the most likely etiology of our patient's supraspinatus tendon subacromial impingement and shoulder pain. Examples of extrinsic primary impingement include thickening of the coracoacromial ligament and a hook-shaped acromial scapular bone because a hook-shaped acromial bone is more likely to be present in patients with subacromial impingement syndrome and with patients with rotator cuff tears compared to patients who have a flat- or curveshaped acromial bone [7]. Emergency physicians should consider the diagnosis of supraspinatus tendon calcification with subacromial impingement syndrome in patients with shoulder pain to expedite urgent musculoskeletal specialist referral.

Radiologists have developed a full five-step ultrasonographic shoulder protocol that includes evaluation of the following structures: the long head of the biceps brachii tendon, the subscapularis tendon, the supraspinatus tendon and rotator interval with both static and dynamic evaluation for subacromial impingement, the acromioclavicular joint, and the infraspinatus and teres minor tendons with the posterior glenoid labrum [10]. The performed ultrasonography is $79 \%$ sensitive and $88 \%$ specific for diagnosing supraspinatus tendon calcification and impingement syndrome using dynamic maneuvers such as humerus abduction [11]. One of the key pitfalls for all musculoskeletal ultrasound examinations is anisotropy artifact that requires perpendicular insonation of tendons, ligaments, muscle, and nerves to observe the correct echotexture of the structures [10]. Another pitfall is the improper positioning of the shoulder in visualizing the supraspinatus tendon. Radiologists have also developed specific sonographic signs of shoulder subacromial impingement such as pooling of fluid laterally to the subdeltoid portion of the subacromial-subdeltoid bursa while the humerus is abducted [5]. Our patient had excellent internal and external rotation motor strength of her shoulder, and she stated no tenderness over her long head of the biceps tendon. A focused point-of-care emergency department bedside ultrasound examination was performed over her supraspinatus tendon, and this revealed calcification near the attachment to the greater tuberosity of the humerus; a dynamic bedside ultrasound long-axis evaluation of the patient's supraspinatus tendon showed elevation of the greater tuberosity cranially to the level of the acromion and impingement of the supraspinatus tendon underneath the acromion of the scapula when the patient actively abducted her left humerus. A complete evaluation of our patient's supraspinatus tendon was obstructed by the calcifications in her supraspinatus tendon, and which may have hidden a partial rotator cuff tear.

Musculoskeletal ultrasonography is an operator-dependent imaging modality, yet the inter-rater reliability of shoulder ultrasonography performed in the radiology department to detect supraspinatus tendon calcification among inexperienced radiologists (6 months of experience) versus experienced radiologists (6 years of experience) has been reported as kappa of 0.70 to 0.83 , substantial agreement [12]. No reliability data are currently available for emergency physicians in performing shoulder ultrasonographic examinations.

The initial treatment for supraspinatus tendon calcification with subacromial impingement syndrome is pain control and rest, as some patients will improve with conservative therapy [1]. Many additional treatment modalities for supraspinatus tendon calcification with subacromial impingement syndrome are available including extracorporeal shock wave therapy, diathermy hyperthermia therapy, ultrasound-guided percutaneous needle aspiration and lavage, and more invasive arthroscopic and open orthopedic surgical procedures [13-20]. Patients with supraspinatus tendon calcification with subacromial impingement syndrome, who undergo ultrasound-guided percutaneous needle aspiration and lavage with corticosteroid injections into the subdeltoid-subacromial bursa have been found to have prompt shoulder function recovery after the procedure and better outcomes at 1-year follow-up; however, at five and ten years, the non-needle aspirated and lavage group reported outcomes similar to the needle aspirated and lavage group [20]. Emergency department primary therapy will include oral pain medication, rest, provision of an arm 
sling, and urgent musculoskeletal specialist referral. Emergency department ultrasonography can help in preventing missed or delayed diagnosis of supraspinatus tendon calcification with subacromial impingement syndrome when the diagnosis is not always clear clinically, and bedside point-of-care ultrasound is of great utility in cases where physical examination maneuvers can be limited by pain and soft tissue swelling.

\section{Conclusion}

Emergency-physician performed bedside point-of-care shoulder musculoskeletal ultrasonography can assist in the rapid diagnosis of supraspinatus tendon calcification and impingement syndrome in the emergency department. Rapid diagnosis of supraspinatus tendon calcification and impingement syndrome can expedite shoulder musculoskeletal consultation and treatment.

\section{Consent}

Written informed consent was obtained from the patient for publication of this Case Report and any accompanying images. A copy of the written consent is available for review by the Editor-in-Chief of this journal.

\section{Additional files}

Additional file 1: Emergency Department ultrasonography bedside diagnosis of supraspinatus tendon calcification. Video of long-axis evaluation of the supraspinatus tendon calcification near the humerus greater tuberosity attachment.

Additional file 2: Emergency Department ultrasonography bedside diagnosis of supraspinatus tendon impingement syndrome. Video of long-axis evaluation of the supraspinatus tendon impingement underneath the acromion of the scapula.

\section{Competing interests}

The authors declare that they have no competing interests.

\section{Authors' contributions}

DR, MK, TW, YA, RG, and AF drafted and edited the manuscript. All authors read and approved the final manuscript.

\section{Authors' information}

DR is the Director of Emergency Ultrasonography and Ultrasound Research. MK and YA are emergency department nurses. TW and RG are physician assistants at the Emergency Medicine Department, Columbia University Medical Center, New York. AF is an emergency medicine resident in the New York Presbyterian, Columbia/Cornell training program, New York.

Received: 26 September 2012 Accepted: 28 January 2013 Published: 11 February 2013

\section{References}

1. Speed CA, Hazleman BL (1999) Calcific tendinitis of the shoulder. N Engl J Med 340(20):1582-1584

2. Neer CS II (1972) Anterior acromioplasty for the chronic impingement syndrome in the shoulder: a preliminary report. J Bone Joint Surg Am 54(1):41-50

3. Neer CS II (1983) Impingement lesions. Clin Orthop Relat Res 173:70-77

4. Hawkins RJ, Kennedy JC (1980) Impingement syndrome in athletes. Am J Sports Med 8(3):151-158
5. Farin PU, Jaroma H, Harju A, Soimakallio S (1990) Shoulder impingement syndrome: sonographic evaluation. Radiology 176(3):845-849

6. Van Holsbeeck E, Declercq G, Derijcke J, Martens M, Verstreken J, Fabry G (1991) Shoulder impingement syndrome. Acta Orthop Belg 57(1):25-29

7. Bigliani LU, Levine WN (1997) Subacromial impingement syndrome. J Bone Joint Surg Am 79(12):1854-1868

8. Garcia GM, McCord GC, Kumar R (2003) Hydroxyapatite crystal deposition disease. Semin Musculoskelet Radiol 7(3):187-193

9. Bittmann S (2006) Calcific tendinitis of the supraspinatus tendon in children. Klin Padiatr 218(1):45-46

10. Jacobson JA (2011) Shoulder US: anatomy, technique, and scanning pitfalls. Radiology 260(1):6-16

11. Read JW, Perko M (1998) Shoulder ultrasound: diagnostic accuracy for impingement syndrome, rotator cuff tear, and biceps tendon pathology. J Shoulder Elbow Surg 7(3):264-271

12. O'Connor PJ, Rankine J, Gibbon WW, Richardson A, Winter F, Miller JH (2005) Interobserver variation in sonography of the painful shoulder. J Clin Ultrasound 33(2):53-56

13. Hearnden A, Desai A, Karmegam A, Flannery M (2009) Extracorporeal shock wave therapy in chronic calcific tendonitis of the shoulder-is it effective? Acta Orthop Belg 75(1):25-31

14. Gimblett PA, Saville J, Ebrall P (1999) A conservative management protoco for calcific tendinitis of the shoulder. J Manipulative Physiol Ther 22(9):622-627

15. Di Cesare A, Giombini A, Dragoni S, Agnello L, Ripani M, Saraceni VM, Maffulli N (2008) Calcific tendinopathy of the rotator cuff. Conservative management with $434 \mathrm{Mhz}$ local microwave diathermy (hyperthermia): a case study. Disabil Rehabil 30(20-22):1578-1583

16. Comfort TH, Arafiles RP (1978) Barbotage of the shoulder with imageintensified fluoroscopic control of needle placement for calcific tendinitis. Clin Orthop Relat Res 135:171-178

17. Farin PU, Rasanen H, Jaroma H, Harju A (1996) Rotator cuff calcifications: treatment with ultrasound-guided percutaneous needle aspiration and lavage. Skeletal Radiol 25(6):551-554

18. del Cura JL, Torre I, Zabala R, Legórburu A (2007) Sonographically guided percutaneous needle lavage in calcific tendinitis of the shoulder: short- and long-term results. AJR Am J Roentgenol 189(3):W128-W134

19. Maugars Y, Varin S, Gouin F, Huguet D, Rodet D, Nizard J, N'Guyen JM, Guillot P, Glémarec J, Passutti N, Berthelot JM (2009) Treatment of shoulder calcifications of the cuff: a controlled study. Joint Bone Spine 76(4):369-377

20. Serafini G, Sconfienza LM, Lacelli F, Silvestri E, Aliprandi A, Sardanelli F (2009) Rotator cuff calcific tendonitis: short-term and 10-year outcomes after twoneedle US-guided percutaneous treatment-nonrandomized controlled trial. Radiology 252(1):157-164

doi:10.1186/2036-7902-5-2

Cite this article as: Riley et al:: Emergency department diagnosis of supraspinatus tendon calcification and shoulder impingement syndrome using bedside ultrasonography. Critical Ultrasound Journal 2013 5:2.

\section{Submit your manuscript to a SpringerOpen ${ }^{\circ}$ journal and benefit from:}

- Convenient online submission

- Rigorous peer review

- Immediate publication on acceptance

- Open access: articles freely available online

- High visibility within the field

- Retaining the copyright to your article

Submit your next manuscript at $>$ springeropen.com 